\title{
Delayed emergence from anesthesia resulting from posterior cerebral artery infarction after Guglielmi detachable coil embolization
}

\author{
Chan Woo Cho, Byung Gun Kim, Hyo-Seok Na, Eun Su Choi, and Young-Tae Jeon \\ Department of Anesthesiology and Pain Medicine, Seoul National University Bundang Hospital, Seongnam, Korea
}

In the treatment of unruptured intracranial aneurysms, Guglielmi detachable coil (GDC) embolization is a good alternative to surgical clipping which requires invasive surgery [1]. The authors experienced a delayed emergence from anesthesia in a post anesthesia care unit (PACU) after GDC embolization of an unruptured intracranial aneurysm under general anesthesia. We report a case of a thromboembolism at the Lt. posterior cerebral artery detected on an angiogram that was immediately performed after a neurologic deficit was detected in the patient.

A 70 -year-old male $(169 \mathrm{~cm}, 74 \mathrm{~kg}$ ) was admitted for the treatment of a $6 \mathrm{~mm}$ unruptured basilar top aneurysm that had been incidentally found during a work up for lung cancer. He was on hypertension and diabetes mellitus medications and had taken aspirin with clopidogrel for 5 days prior to the procedure. Routine laboratory tests were unremarkable and he did not have any neurologic deficit on admission.

Bispectral index monitoring was added to the routine monitoring and general anesthesia was induced with intravenous propofol $120 \mathrm{mg}$, alfentanil $400 \mu \mathrm{g}$ and rocuronium $50 \mathrm{mg}$. After tracheal intubation, deep anesthesia was maintained with $6 \%$ desflurane in $50 \%$ oxygen with nitrous oxide to secure immobility during the procedure. Phenylephrine was continuously infused to compensate for the hypotension. There was no remarkable event during the procedure.

Glycopyrrolate $0.4 \mathrm{mg}$ and neostigmine $1.5 \mathrm{mg}$ were administered after the completion of the procedure. The patient was extubated after confirmation that the bispectral index had reached 80 and self respiration had sufficiently recovered. The patient opened his eyes when his name was called. The procedure took 45 minutes and the total anesthesia time was $70 \mathrm{~min}$ utes. The total dosage of rocuronium was $60 \mathrm{mg}$.

In the PACU, oxygen supplementation of $5 \mathrm{~L} / \mathrm{min}$ with a facial mask was sufficient to maintain the $\mathrm{SpO}_{2}$ at $100 \%$, but the patient could not obey commands and looked uncomfortable while breathing. The blood pressure and heart rate were stable and the tympanic membrane temperature was $35.8^{\circ} \mathrm{C}$. To rule out the possibility of incomplete recovery from the neuromuscular blocking agent, additional glycopyrrolate $0.2 \mathrm{mg}$ and neostigmine $1.0 \mathrm{mg}$ were injected intravenously. Muscle relaxation was monitored with an electrical stimulator by applying the train-of-four method on the ulnar nerve: 4/4. Arterial blood gas analysis showed the following: $\mathrm{pH}$ 7.32, $\mathrm{PaCO}_{2} 31 \mathrm{mmHg}, \mathrm{PaO}_{2}$ $151 \mathrm{mmHg}$, and $\mathrm{HCO}^{3-} 16.2 \mathrm{mM} / \mathrm{L}$. The serum sodium level was $129 \mathrm{mEq}$ and the serum potassium level was $4.84 \mathrm{mEq}$ on laboratory testing. Regular insulin (5 units) was injected intravenously based on the blood sugar test result which was $292 \mathrm{mg} / \mathrm{dl}$.

Considering the possible causes of delayed emergence, a neurologic examination was done. Unfortunately, both pupils were dilated and fixed at $5 \mathrm{~mm}$. The transfemoral cerebral angiography (TFCA) showed decreased blood flow of the Lt. posterior cerebral artery due to a thrombus at the Lt. P1 segment (Fig. 1). After performing mechanical thrombectomy using a Solitare stent (ev3 inc., California, USA), chemical thrombolysis was done with urokinase $460 \mathrm{kIU}$, and tirofiban $900 \mu \mathrm{g}$ for the residual thrombus. The rechecked TFCA showed restoration of the blood flow. The patient was transferred to the intensive care

Corresponding author: Young-Tae Jeon, M.D., Ph.D., Department of Anesthesiology and Pain Medicine, Seoul National University Bundang Hospital, 82, Gumi-ro 173 Beon-gil, Bundang-gu, Seongnam 463-707, Korea. Tel: 82-31-787-7506, Fax: 82-31-787-4063, E-mail: ytjeon@snubh.org (c) This is an open-access article distributed under the terms of the Creative Commons Attribution Non-Commercial License (http:// creativecommons.org/licenses/by-nc/3.0/), which permits unrestricted non-commercial use, distribution, and reproduction in any medium, provided the original work is properly cited. 


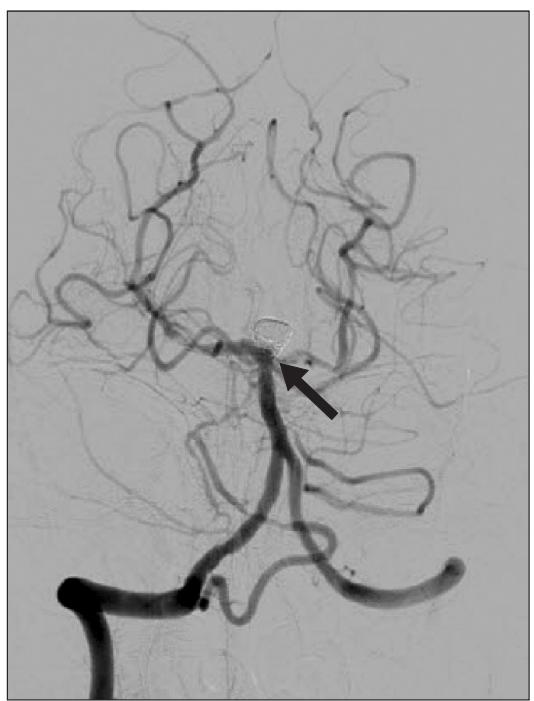

Fig. 1. Postoperative TFCA showing P1 thrombosis.

unit for further management.

In one hour, the patient regained consciousness and was able to grab with the hand or lift his leg but he could not fully open his eyes. Therapeutic hypertension with a target systolic blood pressure of 150 to $180 \mathrm{mmHg}$ was applied for 2 weeks. Four weeks later the patient was moved to a general ward and active rehabilitation was started. The ptosis with extraocular muscle weakness of the left eye and the decreased lower motor power remained unchanged. Two months later the patient was moved to a long term hospital and is currently on a gait rehabilitation program.

Thrombosis in GDC embolization is not an uncommon complication, and an incidence rate of $28 \%$ has been reported in previous studies [2]. It is especially associated with largediameter aneurysms, the balloon-assisted technique, and long procedure times [3]. But there has not been any case report of a thromboembolic event occurring during the stage of emergence from anesthesia in the PACU. In this case, the immediate post- procedural TFCA was intact so we postulate that the thromboembolism occurred during the emergence from anesthesia.

In general, the causes of prolonged unconsciousness after anesthesia are the residual effects of the anesthetics and neuromuscular blocking drugs, hypoxia or hypercapnia, hypoglycemia or hyperglycemia, hypothermia, uremia, electrolyte imbalance and neurologic causes. Because the time needed to emerge to full consciousness is affected by multiple factors such as age, genetic variations, underlying diseases, anesthetic factors, duration of surgery and painful stimulation [4], there is no consensus on the temporal definition of delayed emergence from general anesthesia.

In the management of general anesthesia in interventional neuroradiology, there is no clear superiority of one anesthetic over another in terms of pharmacologic protection against neuronal injury. Nitrous oxide could perhaps be avoided considering the possibility of air embolism, but there is no data supporting this theory.

The patient showed symptoms of a bilateral thalamic infarct resulting from infarction of a unilateral thalamic branch of the posterior cerebral artery, the artery of Percheron. Considering the rich collateral flow of the circle of Willis, blood flow from the Lt. posterior communicating artery could have prevented the patient's complication despite the thrombosis of the Lt. P1 segment. Steinberg et al. [5] reported the close relationship between infarction incidence and the diameter of the posterior communicating artery in basilar artery infarction cases, especially when the diameter was less than $1 \mathrm{~mm}$. Although the patient's Lt. posterior communicating artery was only $0.8 \mathrm{~mm}$ on preoperative brain magnetic resonance angiography, deliberate hypertension was applied to augment the collateral perfusion from the onset of the ischemic event.

This case report is a warning that a procedure-related ischemic event after GDC embolization can occur in the immediate postoperative period, even in the PACU. Meticulous vigilance is needed during the emergence period, especially when a high risk intravascular procedure such as GDC embolization has been performed on the patient.

\section{References}

1. Brilstra EH, Rinkel GJ, van der Graaf Y, van Rooij WJ, Algra A. Treatment of intracranial aneurysms by embolization with coils: a systematic review. Stroke 1999; 30: 470-6.

2. Soeda A, Sakai N, Sakai H, Iihara K, Yamada N, Imakita S, et al. Thromboembolic events associated with Guglielmi detachable coil embolization of asymptomatic cerebral aneurysms: evaluation of 66 consecutive cases with use of diffusion-weighted MR imaging. AJNR Am J Neuroradiol 2003; 24: 127-32.

3. Ko JH, Kim YJ, Cho JS, Cho KT, Park BJ, Cho MK. The analysis of procedural complications of endovascular aneurysm coiling with GDC. J Korean Neurosurg Soc 2004; 36: 394-9.

4. Sinclair RC, Faleiro RJ. Delayed recovery of consciousness after anaesthesia. CEACCP 2006; 6: 114-8.

5. Steinberg GK, Drake CG, Peerless SJ. Deliberate basilar or vertebral artery occlusion in the treatment of intracranial aneurysms: Immediate results and long-term outcome in 201 patients. J Neurosurg 1993; 79: 161-73. 